Document downloaded from:

http://hdl.handle.net/10251/82516

This paper must be cited as:

Deste Cukierman, P.; Mahdi, S.; Neely, A.; Rentocchini, F. (2012). Inventors and entrepreneurs in academica: what types of skills and experience matter?. Technovation. 32(5):293-303. doi:10.1016/j.technovation.2011.12.005.

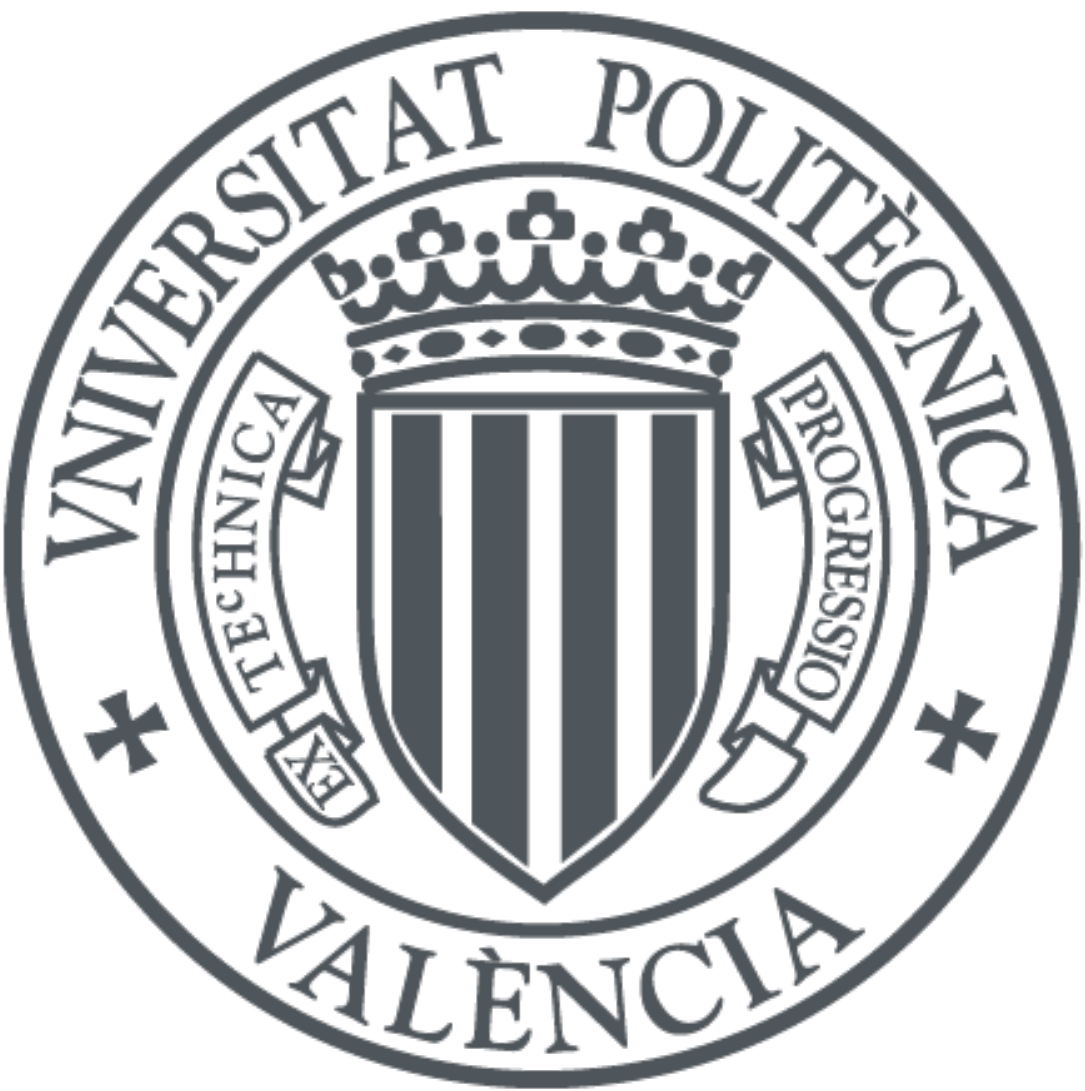

The final publication is available at

http://doi.org/10.1016/j.technovation.2011.12.005

Copyright Elsevier

Additional Information 


\title{
Inventors and entrepreneurs in academia: what types of skills and experience matter?
}

\author{
Pablo D’Este ${ }^{\mathrm{a}}$, Surya Mahdi ${ }^{\mathrm{b}}$, Andy Neely ${ }^{\mathrm{c}}$ and Francesco Rentocchini ${ }^{\mathrm{a}, \mathrm{d}}$
}

\author{
${ }^{a}$ INGENIO, \\ CSIC-UPV, Spanish Council for Scientific Research \\ Universidad Politecnica de Valencia \\ Camino de Vera s/n Edificio 8E \\ Valencia 46022, Spain \\ Email: pdeste@,ingenio.upv.es \\ Telephone: 34963877048 / Fax: 34963877991 \\ (Corresponding author)
}

${ }^{\mathrm{b}}$ Cranfield School of Management,

Cranfield University,

Bedfordshire, MK43 0AL, UK.

c Judge Business School,

University of Cambridge,

Cambridge, CB2 1AG, UK.

${ }^{\mathrm{d}}$ Department of Economics

University of Trento

Via Inama 5

Trento, IT

KEYWORDS: Technological opportunities, entrepreneurial opportunities, discovery and exploitation, research skills, collaboration experience with industry, academic entrepreneurship, spin-offs, patenting. 


\title{
Inventors and entrepreneurs in academia: what type of skills and experience matter?
}

\begin{abstract}
This paper aims to improve our understanding of the attributes of academic researchers that influence the capacity to contribute to technical advance, by either adding to the pool of technological opportunities available to industry or engaging in the exploitation of entrepreneurial opportunities themselves. We investigate a number of factors associated with the skills developed by academic researchers. We find that contributions to the pool of technological opportunities and exploitation of entrepreneurial opportunities in some cases are shaped by different factors and in others have common determinants. Our results show that contributions to technological opportunities are driven by the scientist's academic research excellence and previous discovery of technological opportunities, while exploitation of entrepreneurial opportunities is driven by previous collaboration with industry partners, scientific breadth and previous technological discovery experience.
\end{abstract}




\section{INTRODUCTION}

Public research organizations, particularly universities, are becoming increasingly entrepreneurial, focusing on the realization of commercial value from research and searching for new organizational arrangements that produce a closer alignment between scientific research and innovation (OECD, 2003; Siegel, 2006; Rothaermel et al., 2007). The entrepreneurialism of universities is epitomised by the rise in patenting, licensing and creation of spin-off companies by academic researchers (Wright et al., 2007; Siegel et al., 2003). Evidence of different entrepreneurial performance among academics has highlighted the need to understand what distinguishes academic researchers in terms of their inclination to engage in knowledge transfer activities and, especially, to become academic entrepreneurs (Bercovitz and Feldman, 2008; Hoye and Pries, 2009).

Scholars in the fields of entrepreneurship and innovation studies have long been interested in the entrepreneurial behaviour of university researchers and universities' entrepreneurial activities more generally (Chrisman et al., 1995; Stuart and Ding, 2006; Rothaermel et al., 2007). However, little is known about the skills developed by academic researchers that influence their capacity to contribute to the pool of technological opportunities available to industry as opposed to influencing their capacity to engage in the exploitation of entrepreneurial opportunities. To our knowledge, no study examines the extent academic attributes influence in distinct ways the discovery of technological opportunities and the exploitation of entrepreneurial opportunities. A better understanding of the entrepreneurial process would provide an important contribution to the academic entrepreneurship literature 
and the innovation literature would benefit from an investigation into the factors that contribute to the rate of technological advance from university research. The paper examines several researcher characteristics associated with the discovery of technological opportunities and the exploitation of entrepreneurial opportunities including: a) knowledge of the marketplace and collaboration with users; b) prior experience in invention activity; c) integration of multiple fields of research; d) excellence of research; and e) extent of participation in a wide research network.

We contribute to the literature on academic entrepreneurship in two ways. First, we show that the determinants of academics' contributions to technological opportunities and the entrepreneurial exploitation of these opportunities are driven by different skills. We find that previous collaboration with industry and breadth of scientific knowledge influence the researcher's possibility to seize entrepreneurial opportunities. We find also that scientific excellence is the main driver of discovery, whose results add to the pool of technological opportunities available to industry from university research. We show also that prior invention experience affects both the discovery and the exploitation of technological opportunities.

The paper is structured as follows. Section 2 discusses the conceptual background and proposes a set of hypotheses. Section 3 provides a detailed description of the design of the empirical research. Section 4 presents the results, and Section 5 concludes.

\section{BACKGROUND LITERATURE AND HYPOTHESES}




\subsection{Discovery of technological opportunities and exploitation of entrepreneurial opportunities}

The literature on entrepreneurship defines it as being concerned with the discovery, evaluation and exploitation of profitable opportunities, and points to a number of extensions to inform theory and empirical analysis (Venkataraman, 1997; Shane and Venkataraman, 2000; Eckhardt and Shane, 2003). One of these is related to the distinction between the sources of opportunities and their enactment (via identification and exploitation) (Shane and Venkataraman, 2000; Eckhardt and Shane, 2003). The literature on academic entrepreneurship is focusing increasingly on these notions, recognizing them as distinct and crucial for the study of entrepreneurship (Eckhardt and Shane, 2003; Wright et al., 2004; Park, 2005).

In discussing opportunity sources, Eckhardt and Shane (2003) emphasize the role of shifts in the pool of technological opportunities catalysed by the creation of new knowledge. Klevorick et al. (1995) define technological opportunities as comprising the set of possibilities for technological advance available to industry at any given point in time, which contribute to shaping the level of industry R\&D and rate of product and process innovation. Technological advances based on university research are among the main sources of new contributions to the pool of technological opportunities. Indeed, technological opportunities based on the creation of new technical knowledge by academia have become an important source of opportunities for enhancing industrial innovation performance (Mansfield, 1995, Bierly et al., 2009, Bishop et al, 2011). Academic inventors are the main university actors and contribute 
to the pool of new technological possibilities, expanding the horizon of profitable entrepreneurial opportunities available to firms. ${ }^{1}$

In terms of their enactment, Shane and Venkataraman (2000) propose that entrepreneurial opportunities exist when new means-ends relationships emerge in product markets, factor markets or new materials (among other alternatives). The existence of an entrepreneurial opportunity is not enough to establish entrepreneurship: the individual must be able to recognize an opportunity and its value, and be able also to guide the resource allocation decisions of others (identification). Additionally, the potential entrepreneur must decide to exploit the opportunity: that is, to acquire resources and engage in activities that change prices and generate entrepreneurial profit (exploitation).

The contributions of academic researchers to the pool of technological opportunity sources are often seen as equating with invention disclosure to university technology transfer offices and academic patenting (Jensen and Thursby, 2001; Colyvas et al., 2002; Shane, 2002; Jensen et al., 2003; Lubango and Pouris, 2007). Jensen and Thursby (2001) show that a large majority of university inventions disclosed (over $75 \%$ ) are no more than a proof of concept at the time of licence, indicating the embryonic state of most of the technologies in academic patents. The rationale behind regulations encouraging university patenting is that intellectual property rights favour the realization of academic inventions into practice. They encourage firms to invest

\footnotetext{
${ }^{1}$ Note that, as Klevorick et al. (1995) point out, there are many different ways that university research can contribute to the pool of technological opportunities including production of basic and applied research, which increases the available theory and data and enables better fundamental understanding. Here we concentrate on the direct contribution of academic research to the pool of technical advances from university research as one of the sources of technological opportunity highlighted by Klevorick et al. (1995) - i.e. technological advances that originate outside the industrial chain.
} 
resources in inventions that require a protracted development trajectory before they become an innovation, in exchange for a licence agreement with the university (Jensen and Thursby, 2001; Colyvas et al., 2002; Mowery and Sampat, 2005). Several authors show that patents play a role in the creation of new firms and that researchers engaged in activities linked to the protection of intellectual property are more likely to create spin-offs than those engaged in other work (Landry et al., 2007, 2010). The probability of an invention being commercialized through new firm creation is governed by certain characteristics (see Shane, 2001a,b), but academic inventions and patents are increasingly seen as important sources of technological and profitable opportunities (Shane, 2001a,b; Lowe \& Ziedonis, 2006). We would argue that academic patents are a good expression of early stage inventions, and constitute the sources of potential technological and entrepreneurial opportunities but which are far from commercial use.

Opportunities can be exploited by academic researchers setting up businesses in order to realize the market potential of their discoveries. In this case, commercialization activity is not limited to identifying a technological breakthrough, but extends to the activities related to bringing an invention to the market (Mustar, 1997). These include design of a business plan, obtaining venture capital and managing (or advising on) the manufacturing and commercialization activities of the new company. Establishing a firm is not the only route to the commercialization of academic inventions; patenting and licensing to non-academics allow the appropriate of the returns from innovation (Shane, 2002). However, in this paper we focus on setting up businesses and equity ownership by academics since these actions capture a more direct and comprehensive engagement in the exploitation of entrepreneurial opportunities. We study 
involvement in the wide range of activities associated with materializing new goods or services and the organization of methods that allow outputs to be sold at more than their cost of production (Shane, 2000).

The literature on academic entrepreneurship research is rather vague about the factors that contribute to the development of entrepreneurial skills among academic scientists - particularly the skills required to build technological opportunity sources and enable their exploitation. The literature suggests that prior knowledge of markets and customers' problems positively contributes to the development by academic researchers of new discoveries and technological breakthroughs and leads to potential commercial opportunities (Shane, 2000). However, discovery of a technological opportunity does not equate with realized, valuable commercial exploitation. Identifying a technological breakthrough is qualitatively different from bringing to market a new technology. Exploitation of a potentially profitable opportunity is likely to require different skills from those involved in its discovery.

Although both patenting and spin-off activity may be motivated by the desire of the academic researcher to exploit an invention originating in the university, spin-offs involve the specific activity of creating an independent venture to exploit the invention, while patenting can be seen as the expression of a source for technological advance. In the latter case, the inventor does not necessarily perceive the invention as having direct commercial potential. This distinction is central to our discussion: it clearly expresses the idea that patenting is associated with exploring an opportunity 
and adding to the pool of technological opportunity sources, while spin-off activity is associated with the exploitation of a technological opportunity for profit. ${ }^{2}$

\subsection{Factors influencing discovery of technological opportunities and exploitation}

\section{of entrepreneurial opportunities}

The literature on academic entrepreneurship highlights the importance of understanding the factors shaping the behaviour of academic entrepreneurs, and particularly the factors that influence the development of entrepreneurial skills in academic researchers. Entrepreneurship research is a natural starting point for the search for a conceptual framework to investigate these issues; this literature is concerned with why some (and not other) researchers discover opportunity sources and exploit entrepreneurial opportunities.

Drawing on the entrepreneurship research literature on the importance of prior knowledge and idiosyncratic experience to explain entrepreneurial behaviour, we identify several factors that might influence the capacity of academic researchers to discover technological opportunities and exploit them. These factors fall into three groups. First, the research skills developed by academics, which include i) excellence of academic research and ii) integration of multiple fields of research in their research activities. Second, the technological skills developed by academics, which include prior invention experience. Third, the stock of idiosyncratic information accumulated through involvement in professional networks, which includes i) knowledge of the

\footnotetext{
${ }^{2}$ We acknowledge that spin-offs can be seen as contributing to the pool of technical advancements from university research because they provide information to industry on new available technological opportunities. However, our distinction is related to the deliberate, intended enactment of an entrepreneurial opportunity in search of profit. The discovery of technological breakthroughs, and technological inventions more generally, may not involve any deliberate intention to pursue further commercial or entrepreneurial opportunities.
} 
marketplace through collaboration with users and ii) access to new research ideas through collaboration in academic research networks.

More importantly, we discuss why the discovery of technological opportunities and the exploitation of entrepreneurial opportunities are sometimes shaped by different factors and in other cases have common determinants. We examine these factors and propose a set of hypotheses.

\subsubsection{Excellence of academic research}

Academic entrepreneurship research shows that working at the frontier gives academic scientists comparative advantage for identifying new breakthrough opportunities (Zucker et al., 1998; Franzoni and Lissoni, 2007). There is a large body of empirical research showing that researchers who are very active contributors to the pool of technological opportunities, tend to be particularly prominent in their respective fields. For instance, Meyer (2006) shows that academic researchers who engage in frequent patenting activity are also more productive in terms of publishing. Similarly, Louis et al. (1989), Deeds et al. (1997), Powers and McDougall (2005) and Landry et al. (2007) (among others) consistently find that academic engagement in knowledge transfer activities is positively associated with superior academic performance.

However, while much of the evidence in the academic entrepreneurship literature shows that knowledge transfer activities generally originate in good research conducted by successful scientists in the field (Etzkowitz, 1989), we investigate whether the research performance of a scientist is more strongly associated with the 
discovery of technological opportunities or the exploitation of entrepreneurial opportunities.

Academics involved in frontier research may be more likely to generate new inventions or technological breakthroughs (i.e. increasing the pool of opportunity sources). There is increasing evidence of a relationship between scientific excellence, in the form of 'star scientists', and involvement in successful entrepreneurial ventures (Zucker et al., 1998). Therefore, we would expect that conducting high impact research may be particularly conducive to both the creation of new technological opportunities and the exploitation of entrepreneurial opportunities. Nevertheless we would expect the effect to be stronger in the case of discovery of technological opportunities. This derives from the importance of the concept of 'dual knowledge' (Murray and Stern, 2007) according to which, a single discovery may contribute to both scientific research and useful commercial application. In particular, discovery is likely to be realized contemporaneously as a scientific research article and a patent, but it does not necessarily favour the decision to act upon such opportunities in the pursuit of commercial or profitable outcomes. Thus, we propose the following hypotheses:

H1a. Scientific excellence has a positive effect on the discovery of technological opportunities and on the exploitation of entrepreneurial opportunities.

H1b. The effect of scientific excellence is higher for the discovery of technological opportunities than for the exploitation of entrepreneurial opportunities.

\subsubsection{Integration of multiple fields of research}


Entrepreneurship research shows that individuals with interdisciplinary backgrounds are better placed to recognize and act upon innovation opportunities (Venkataraman, 1997; Shane, 2000; Bercovitz and Feldman, 2008). Individuals who are able to integrate different bodies of knowledge in their research activities and, therefore, are familiar with multiple methodological perspectives, are particularly likely to develop the skills required to propose novel approaches and to bridge the worlds of scientific research and application. For instance, Bercovitz and Feldman (2008) show that academic researchers integrating multiple fields of research are more likely to disclose inventions to their university technology transfer offices. According to this literature, we could expect that academic scientists who manage to integrate different bodies of knowledge in their research activities are more likely to consider the various uses and applications of their research and be more aware of its commercial potential. Shane (2000) shows that individuals with direct manufacturing experience combined with a strong scientific research profile are particularly capable of exploiting business opportunities. Exploitation of entrepreneurial opportunities involves mastery of a wider range of skills and assumption of managerial responsibility compared to discovery of a technological opportunity. For instance, according to Tijssen (2006), creating a spin-off involves the development and exchange of marketable products, which require the effective organization of different functions, which is much more onerous than recognizing that an invented technology has potential and preparing a patent application.

Therefore, we would expect that academics integrating different fields of research should be more likely to engage in the exploitation of entrepreneurial opportunities (compared to academics specialized within narrow disciplinary fields). Indeed, while 
the breadth of the scientific work of academics may be an asset for combining multiple bodies of knowledge which, eventually, might result in the exploitation of entrepreneurial opportunities, expansion of the pool of opportunity sources is likely to benefit more from the researcher's depth of knowledge (Wu and Shanley, 2009). We would expect the integration of multiple bodies of research to be more important for the exploitation of entrepreneurial opportunities than for the discovery of technological opportunities. In line with these arguments, we propose the following hypotheses:

H2a. The integration of multiple fields of research has a positive effect on both the discovery of technological opportunities and the exploitation of entrepreneurial opportunities.

$\mathrm{H} 2 \mathrm{~b}$. The effect of the integration of multiple fields of research is higher for the exploitation of entrepreneurial opportunities than for the discovery of technological opportunities.

\subsubsection{Prior invention experience}

Entrepreneurship research highlights that being inventive increases the probability of discovery of technological opportunities and exploitation of entrepreneurial opportunities, since it helps to develop the necessary mindset and skills (Shane and Venkataraman, 2000; Shane, 2000). Prior invention experience in terms of time spent on invention disclosure and development of patent applications helps to refine the routines involved in the invention process and increases the ability of the researcher to add to the pool of technological opportunity sources (Bercovitz and Feldman, 2008).

At the same time, prior invention experience may contribute to develop a favourable mindset towards commercialisation of university research, favouring the researcher's willingness towards exploitation of entrepreneurial opportunities. However, prior 
invention experience may also contribute to have a heightened appreciation of the risks associated with, and the complementary assets required for, the exploitation of entrepreneurial opportunities, suggesting that experience may have a weaker impact on opportunity exploitation compared to opportunity discovery (Cooper et al, 1988; Shepherd et al., 2003). In line with these arguments, we propose the following:

H3a. Prior invention experience has a positive effect on both the discovery of technological opportunities and the exploitation of entrepreneurial opportunities.

$\mathrm{H} 3 \mathrm{~b}$. The effect of prior invention experience is higher for the discovery of technological opportunities than for the exploitation of entrepreneurial opportunities.

\subsubsection{Experience of collaboration with industry}

Entrepreneurship research points to the importance of information transfer from previous experience to a current entrepreneurial opportunity (Shane and Venkataraman, 2000). Collaboration with industry, for example, is experience often identified by the academic entrepreneurship literature as a good predictor of effective technology transfer. For instance, Grandi and Grimaldi (2005) and Landry et al. (2007) show that relational capital in terms of academic researchers' interactions with users, is positively and significantly associated with the extent to which the academic researcher engages in knowledge transfer activities. At the organizational level, Feldman and Desrochers (2004) and Jong (2006) show that universities and departments with a tradition of collaborative research with firms are more likely to recognize the commercial opportunities of their research activities. We propose that collaboration with industry on the one hand, and the awareness and ability to exploit commercial opportunities on the other, are likely to be self-reinforcing. This is because the higher the level of interaction with industry, the more likely it is that 
academic researchers will investigate the potential applications of their research and the better will be their understanding of market conditions and business processes.

While the exploitation of an entrepreneurial opportunity relies more on external knowledge drawn from the entrepreneurial environment (Shane, 2000), the discovery phase of technological opportunities requires the combination of knowledge that is external and internal to the research environment (Landry et al., 2010). We would expect knowledge acquired through collaboration with industry will promote the exploitation of entrepreneurial opportunities rather than discovery of technological breakthroughs.

H4a. Prior experience of research collaboration with industry has a positive effect on both the discovery of technological opportunities and the exploitation of entrepreneurial opportunities.

$\mathrm{H} 4 \mathrm{~b}$. The effect of prior experience of research collaboration with industry is higher for the exploitation of entrepreneurial opportunities than for the discovery of technological opportunities.

\subsubsection{Membership of external academic research networks}

The importance of social networks has long been associated with the enhancement of entrepreneurial skills. Among other benefits, social bonds enhance the opportunity recognition capabilities of entrepreneurs (Hills et al., 1997; Nicolau and Birley, 2003), provide access to critical resources (Aldrich et al., 1987) and enable the entrepreneur to capitalize quickly on market opportunities (Uzzi, 1997; Nicolau and Birley, 2003). For instance, Stuart and Ding (2006) show that exposure to entrepreneur colleagues increases the propensity for an academic to be entrepreneurial. Similarly, Zucker et al. (2002) highlight the importance of the wider social network of academic scientists showing that collaboration between star academic scientists and firms increase the 
research productivity of the latter in terms of products in development and products launched to the market. The crucial factor is the tacit knowledge embodied in individuals which is transferred through collaborative working. Thus, we expect the spread of the cross-institutional research collaboration network to have a positive impact on the exploitation of entrepreneurial opportunities.

Academic research networks with other research organizations represent only a particular sub-group of an academic researcher's social network but, arguably, a very important part of it. Participation in research collaborations is based on access to complementary expertise; access to additional equipment and resources; and acquisition of prestige, visibility and recognition (Bammer, 2008). Cross-institutional collaborations established by researchers frequently are reported as means to mobilize the social resources to achieve the cognitive diversity required for research at the interface between more than one disciplinary field (Rafols, 2008), and to enhance cross-fertilization among disciplines (Bammer, 2008). Consequently, academics with a wide cross-institutional collaboration network are likely to be exposed to multiple research perspectives and methods that can be applied in their research activities, and which favour the discovery of scientific and technological breakthroughs. However, we expect the effect of cross-institutional collaboration network membership to be more important for the discovery of technological opportunities than for the exploitation of entrepreneurial opportunities given the more important role of crossinstitutional collaboration as enabling platforms for research findings. We therefore propose that:

H5a. The breadth of the cross-institutional research collaboration network has a positive effect on the discovery of technological opportunities and the exploitation of entrepreneurial opportunities. 
$\mathrm{H} 5 \mathrm{~b}$. The effect of a wide cross-institutional research collaboration network is higher for the discovery of technological opportunities than for the exploitation of entrepreneurial opportunities.

\section{METHOD}

\subsection{Data Collection}

The analysis builds on four sets of data, combining primary and secondary data sources. In this section we describe the data sources and the connections between them. We exploit data from a survey of UK academic researchers in the Engineering and Physical Sciences asking about their interactions with industry and the commercialization of inventions stemming from their research. The sample of researchers was obtained from the records of principal investigators on projects receiving a grant from the UK Engineering and Physical Sciences Research Council $(\text { EPSRC) })^{3}$ over the period 1999-2003. To ensure that the list of university researchers was representative of the overall population of active researchers, the range of scientific fields was restricted to engineering, chemistry, physics, mathematics and computer science. Since these are the main targets of EPSRC funding, researchers from these disciplinary fields are likely to rely on EPSRC as their primary source of research funding. This sampling strategy resulted in a list of 4,337 university researchers across the UK, all of whom were sent a questionnaire.

The survey was conducted in the first half of 2004 and resulted in 1,528 valid returned questionnaires, a response rate of $35 \%$. There were no statistical differences in the

\footnotetext{
${ }^{3}$ EPSRC distributes funds based on research proposals from mainly university-based investigators, in response to open calls for applications. It distributes over $20 \%$ of the total UK science budget and is responsible for funding research in engineering and the physical sciences. The EPSRC actively encourages partnerships between researchers and potential users of the research, resulting in almost $45 \%$ of EPSRC funded research grants involving partnerships with industry or other stakeholders. Among these, more than $80 \%$ of the collaborative grants for projects in the hard sciences and engineering involve at least one company partner.
} 
response rate across scientific disciplines, which ranged from $30.2 \%$ for computer science to $39.7 \%$ for general engineering (see Table 1, column 3).

[TABLE 1 in here]

We also used data from the 2001 UK Research Assessment Exercise (RAE) for information on the publication profiles of the set of university researchers who responded to the survey. Until 2008, the RAE was the national research evaluation system in the UK and covered all research disciplines and higher education institutions in the UK. Its main purpose was to assist in the allocation of block grant funding according to a retrospective peer-based quality assessment (Barker, 2007; Whitley, 2007). The process required every university 'unit of assessment' (generally corresponding to a department or school) to present several sets of data, including four items of research output per research staff member, produced during the relevant time period (i.e. 1995-2000 in the case of RAE 2001).

Complete copies of submissions, including data on each individual's submitted publications are available on the web; ${ }^{4}$ they provide information on 203,743 different research outputs from 53,455 submitting individuals. Although the large majority of this research output is journal articles $(141,789$ out of 203,743 , i.e. about $70 \%)$, it also includes items such as: patents, book chapters, reports, new designs, artefacts, etc.

For the purpose of this investigation, we are particularly interested in the data providing information on the journal articles submitted for assessment in the RAE.

\footnotetext{
${ }^{4}$ www.hero.ac.uk
} 
Our focus on journal articles is to obtain insights into: a) the type of research conducted by the individual (e.g. degree of collaboration with other institutions and range of subject topics addressed in the research); and b) the quality of research (measured by citations to publications), which we collected from a third source - the Institute for Scientific Information - Web of Science (ISI-WoS).

This third set of data comes from matching the journal articles submitted to RAE 2001 to papers in journals indexed in the WoS. To establish a match, we submitted a query to the WoS based on author name, publication year, journal title and article title, and retrieved citation counts for the matched articles. We applied a cut off for citations within the first five years of publication (including self-citation). This resulted in a match for $91 \%$ of the articles submitted in the RAE 2001 within the fields of Engineering and Physical Sciences identified on the WoS. ${ }^{5}$

The fourth source of data was based on matching the names of the principal investigators in our survey with the names of inventors on patents granted by the European Patent Office (EPO) in the period 1995-2001. The matched fields were researcher name (i.e. last name and initials) and general postcode (i.e. first two letters of the postcode). This identified which of our respondents were inventors (based on EPO patents granted), and the number of patents which named the respondent as the inventor, in the period 1995 to $2001 .^{6}$

\footnotetext{
${ }^{5}$ For further details on the algorithm used to link the individual items of RAE 2001 journal articles with papers in the WoS, see Mahdi et al. (2008).

${ }^{6}$ For further details on this matching procedure see Crespi et al. (2011).
} 
Our use of secondary data sources in addition to the data collected through the survey, was aimed at achieving a robust analysis, providing individual level information that was retrospective, but not self reported, and thereby avoiding problems of reportingbias and simultaneity among our various constructs. However, it reduced our working sample to 916 university researchers, significantly smaller than the original sample of 1,528 survey respondents (see last two columns in Table 1). This smaller sample is a consequence of two mismatches. On the one hand, about $26 \%$ of our 1,528 survey respondent researchers did not appear in the RAE 2001 submission. This was because a proportion of academics who where active researchers in 2004 and responded to our questionnaire were not eligible for inclusion in the 2001 RAE (e.g. they were not permanent staff members or were non-UK researchers at the time ). In fact, this $26 \%$ of non-matched individuals are younger and more junior academics than the researchers in our survey who were included in RAE 2001. As a robustness check, we compared the distribution of our sample across age classes with the same distribution for a more comprehensive sample derived from the CBR/ESRC survey (Abreu et al., 2009). The comparison across different age classes shows that the distribution of academics by age does not differ between the two samples $\left(\chi^{2}(2)=4.95\right)$. We interpret this as evidence of no under-sampling of young researchers in our dataset.

Also, from the 1,125 survey respondents whose work was submitted to RAE 2001, we selected only those for whom we had information on three or four journal articles submitted for assessment. This means that researchers who did not submit a journal article or researchers with less than three articles subsequently matched in the WoS, are excluded from our analysis. The reason for imposing this constraint is that, since a substantial proportion of the measures we use in this paper are based on information 
provided from the papers submitted to the RAE, we decided to limit the sample to researchers with at least three publications matched in the WoS.

Table 1 shows the distribution of researchers across scientific fields in the final sample (i.e. 916 cases), which is largely comparable with the survey population, though there are two notable differences. In particular, we are under-sampling researchers in the fields of computer science and oversampling researchers in the field of chemistry. In the case of computer science, this is likely to be a consequence of the comparatively large proportion of researchers in this field who submitted other types of research outputs to RAE 2001 (e.g. monographs and conference abstracts) (see also Mahdi et al., 2008). Therefore, the criterion of a match in the WoS imposes some constraints on how comprehensively we capture the behaviour of researchers across all the scientific fields in our study.

\subsection{Measurement of constructs}

\subsubsection{Dependent variables}

In order to obtain a measure of the capacity of academic researchers with respect to the discovery of technological opportunities and the exploitation of entrepreneurial opportunities, we draw on the responses to two questions in our survey. The first relates to patenting activities, and asks university researchers to indicate involvement in any sort of patenting activity between 2002 and 2003, including whether the researcher applied for a patent or was recorded as an inventor on a patent applied by a third party. The second question asks university researchers to report on the frequency of their engagement in setting up equity interests in companies and especially establishing spin-off companies, in the period 2002-2003. 
This information allows us to construct two binary variables capturing: a) discovery of technological opportunities (Opportunity Discovery) - proxied by a variable measuring whether the researcher is involved in invention as recorded in patenting activities; and b) exploitation of entrepreneurial opportunities (Opportunity Exploitation) - whether the university researcher participated in the formation of a new company or was involved in setting up an equity interest in a company. For our sample of 916 university researchers, 14\% reported involvement in spin-offs while $29 \%$ reported patenting activity (see Table 2$){ }^{7}$

It should be stressed that patents constitute a widespread instrument to capture information about inventions by academic scientists (Griliches, 1990) and are also an important, albeit not exclusive, source of early stage entrepreneurial opportunity. Landry et al. (2007) show that academic researchers more interested in the protection of intellectual property are more likely to create spin-offs; Prodan and Drnovsek (2010) find that the number of patents is positively related to academicentrepreneurial intentions; and Fini et al. (2010) report that almost $50 \%$ of US academic researchers working in the area of engineering and physics and mathematics who started businesses based them on patents.

[TABLE 2 in here]

\footnotetext{
7 The condition that reduces our sample to 916 cases, does not lead to biases with respect to our dependent variables. We examined whether selecting cases where we had 3 or 4 paper submissions matched in the WoS resulted in under sampling (or oversampling) those individuals that are more likely to engage in discovery or technological opportunities or exploitation of entrepreneurial opportunities. We did this by calculating $\chi^{2}$ difference tests on the proportion of researchers who engage in patenting and spin-off activities, for each scientific discipline. In all cases we found that the proportion of researchers who engage in either patenting or spin-offs does not significantly differ between the sample of individuals with 3 or 4 articles and the sample of individuals with less than 3 articles.
} 
Table 2 presents the differences across disciplinary fields with respect to the extent of entrepreneurialism among university researchers. It shows that the extent of opportunity discovery and opportunity exploitation differs significantly across disciplines, and that entrepreneurship is much more frequent in disciplines such as electrical and electronic engineering and general engineering than in mathematics.

\subsubsection{Explanatory variables}

To measure scientific excellence, we compute the average number of citations to papers submitted to the RAE 2001 within five years after publication. This variable takes a minimum value of zero and a maximum value of 210 citations per submitted paper. To capture the extent to which an individual researcher is able to expand research activities across a range of scientific fields - scientific breadth - we compute the number of research subjects (as reported for each publication in the WoS) associated with the three or four publications submitted to the RAE 2001, to measure the range of research areas that researchers integrated in their research activities. This variable takes a minimum value of 0.25 if the four publications are associated with the same research subject, and a maximum value of 3, meaning that, on average, three distinct scientific areas are integrated (or combined) in the publications reported to RAE 2001.

To measure prior invention experience we compute the number of times the individual researcher is recorded as inventor on an EPO patent over the period 19952001. To measure past collaboration with industry, we consider the number of collaborative grants awarded to the university researcher by the EPSRC over the 
period 1995-2001. To measure the extent of the research network, we compute the natural logarithm of the number of organizations with which the researcher has collaborated, measured by the different institutional addresses on the three or four articles submitted to RAE 2001 (normalized by the number of articles). Different institutional addresses refer to the count of distinct affiliation postcodes appearing on the publications. This variable has a minimum value of 0 if the researcher has not collaborated with authors from another organization, and a maximum of 8 if the researcher has collaborated with authors from eight different institutions, normalized by the number of articles submitted. ${ }^{8}$

\subsubsection{Control variables}

Since some individual characteristics may favour (or reduce) university researcher participation in entrepreneurial activities, we include in our analysis some individual features that might promote a disposition for entrepreneurship. First, we control for individual heterogeneity with regard to behavioural motivations to undertake entrepreneurial activities by assessing the extent to which the researcher operates in a research domain favourable to the discovery of technological opportunities and the exploitation of business opportunities, or whether academic career aspirations are well served by entrepreneurial actions. We compute an inverse scale including six items from the survey: 'The nature of my research is not linked to industry interests or needs'; 'My professional networks include no links with industry'; 'Proprietary knowledge (e.g. patents) is of negligible importance in the field'; 'Collaboration with industry is detrimental to career progression'; 'Interactions with industry conflict with my teaching and research responsibilities'; and 'Difficulty in finding companies with

\footnotetext{
${ }^{8}$ Note that this measure includes different instances of cross-institutional interaction. It may include collaboration across different universities, or between universities and non-university organizations. It may include collaborations between research units on the same university campus.
} 
an appropriate profile'. These six items were scored on a five-point scale from 'not at all', if the item was assessed as not reflecting a constraint to collaboration with industry, to 'very much' if the item was assessed as reflecting a strong barrier to collaboration with industry. The resulting scale is reliable, with a Cronbach's alpha coefficient equal to 0.69 . Second, we include researcher's age (Age) since age is likely to influence engagement in entrepreneurial activities (Bercovitz and Feldman, 2008).

In addition, because certain characteristics of the departments and universities to which researchers are affiliated may influence their disposition to engage in entrepreneurial activities (Tornquist and Kallsen, 1994; Di Gregorio and Shane, 2003; Jensen et al., 2003), we consider some organizational characteristics. We include a proxy for size of the department (department size) measured by the number of individuals from a particular department or school, submitting research outputs to the RAE 2001. To account for an environment favourable to interactions with industry, we include the amount of funding from industry per active researcher (industry funding $p c$, measured in thousands of pounds sterling per capita and logarithmically transformed), using information from units of assessment to the RAE 2001.

We constructed additional control variables to capture the role of the institutional context on the formation of academic spinoffs (Shane and Venkataraman, 2000; Lockett and Wright, 2005). We exploit information available from the 2005 Higher Education, Business and Community Interaction (HEBCI) Survey collected by the Higher Education Funding Council for England, especially responses to question 21: 'Does the HEI offer support for spin-offs through the following mechanisms, either provided by the HEI or in collaboration with a partner organization?'. We calculate 
the number of spin-off mechanisms available at the university level, for each researcher contained in our sample (NSpinoffMechanisms). The variable ranges between 0 and 7 for on-campus incubators, other incubators in the locality, science park accommodation, entrepreneurship training, seed investment, venture capital, and business advice.

We also consider two binary variables for the RAE score awarded to the department: top-ranked, taking the value 1 if the university department was ranked as $5^{*}$; and lowranked, taking the value 1 if the department was ranked 4 or below (the reference category is a score of 5). We also consider a dichotomous variable that takes the value 1 if the university to which a researcher is affiliated belongs to the Russell Group (the group of the largest and most prestigious research universities in the UK). ${ }^{9}$ To account for systematic differences across disciplinary fields, we include nine discipline dummies (with chemistry as the reference category). Finally, we include 13 regional dummies to pick up unexplained heterogeneity across UK regions.

\section{ANALYSIS AND RESULTS}

This section presents the descriptive statistics and relations for the variables included in our analysis, and our results. Table 3 reports the descriptive statistics and bivariate correlations for the variables considered in our analysis and shows that the bivariate correlations among our set of five explanatory variables are generally weakly correlated. There is no indication of significant multi-collinearity amongst the independent variables (i.e. the Variance Inflation Factor ranges from 1.14 to 3.32, well below the threshold level of 5).

\footnotetext{
${ }^{9}$ By 2000, the Russell Group was composed of 17 UK universities. For further details see: www.russell_group.uk
} 
[TABLE 3 in here]

Table 4 presents the results of the probit regression analyses. We report unstandardized estimated coefficients, with robust standard errors in parenthesis. Model 1 relates to 'Discovery of Technological Opportunities (Opportunity Discovery)', and Model 2 to 'Exploitation of Entrepreneurial Opportunities (Opportunity Exploitation)'. Table 4 shows the following results.

[TABLE 4 in here]

The scientific impact - scientific excellence - of research activities has a strong impact on the discovery of technological opportunities, but not on a researcher's exploitation of entrepreneurial opportunities. This result only partially supports hypothesis 1a. The significant effect of scientific excellence on opportunity discovery and its nonsignificant effect on opportunity exploitation, however, provide support for hypothesis $1 \mathrm{~b}$, which proposes a stronger positive effect of scientific excellence on the discovery of technological opportunities than on exploitation of entrepreneurial opportunities.

Scientific breadth has a positive and statistically significant impact only on the exploitation of entrepreneurial opportunities. Therefore, academic researchers with abilities to embrace a broader range of disciplinary fields in their research activities are more likely to exploit entrepreneurial opportunities. These results are consistent with hypothesis $2 \mathrm{~b}$, but only partially support hypothesis $2 \mathrm{a}$, since we do not find a 
positive impact of scientific breadth on either opportunity discovery or opportunity exploitation.

Prior invention experience has a positive and significant impact on 'opportunity discovery' and 'opportunity exploitation'. The difference between the two coefficients is found to be statistically significant $(z=3.13)$ and significantly greater for the case of opportunity discovery. Thus, our results support hypotheses $3 \mathrm{a}$ and $3 \mathrm{~b}$.

Past collaboration with industry shows a positive and significant impact only for the case of 'opportunity exploitation', while there is no statistically significant impact on 'opportunity discovery'. These results provide only partial support for hypothesis 4a: a significant relationship between past collaboration with industry and opportunity exploitation, but not with opportunity discovery. The significant effect of past collaboration with industry on exploitation and its non-significant effect on discovery, however, provides support for hypothesis $4 \mathrm{~b}$, which proposed a stronger positive effect of an academic scientist's prior experience of collaboration with industry on the exploitation of technological opportunities rather than on the discovery of technological opportunities. Finally, research network has no significant effect on the probability of university researchers engaging in the discovery of technological opportunities or in the exploitation of entrepreneurial opportunities. Therefore, we find no support for hypotheses $5 \mathrm{a}$ and $5 \mathrm{~b}$.

With respect to the control variables, Table 4 shows that most control variables have a marginal impact on the probability of engaging in the discovery of technological opportunities or the exploitation of entrepreneurial opportunities. Only behavioural 
motivation for collaboration with industry has a significant and positive impact on both opportunity discovery and opportunity exploitation. Finally, since opportunity discovery and opportunity exploitation are not independent of each other, we conducted a bivariate probit analysis to capture the possible interdependence between these two entrepreneurial functions. Table A1 in the appendix, reports the results for the bivariate probit model, showing that the results are in line with those reported in Table 4.

\section{DISCUSSION AND CONCLUSIONS}

The results have several implications for academic entrepreneurship theory. First, they underline the importance of individual-level features for entrepreneurship and identify a range of knowledge-based backgrounds that favour the entrepreneurial process. In this respect, the findings from this study support the significant role of prior knowledge and experience in the recognition and exploitation of business opportunities (Shane, 2000; Shane and Venkataraman, 2000). These findings indicate that, regardless of the disciplinary field or organizational setting, academic researchers with particular research profiles and/or collaboration experience are more capable of or more willing to contribute to the pool of opportunity sources and to undertake entrepreneurial activities.

Second, the study distinguishes between opportunity discovery and opportunity exploitation, and the results show that some individual level features impact differently on the likelihood of engaging in one or the other activity. While the scientific excellence of the research shapes opportunity discovery, it is the capacity to combine multiple fields of research and experience gained from collaboration with 
users that most distinctively shape opportunity exploitation. Third, we show that prior invention experience affects both opportunity discovery and opportunity exploitation, but the effect is stronger for opportunity discovery. These are important findings since previous research does not focus on these two functions of discovery of opportunity sources and exploitation of entrepreneurial opportunities, simultaneously (Shane, 2000; Wright et al., 2004).

This section discusses the individual level features associated with prior knowledge and experience that are found to influence the discovery of technological opportunities and/or the exploitation of entrepreneurial opportunities.

\section{a) Scientific Excellence}

We observe a significant impact of scientific excellence on an academic researcher's discovery of technological opportunities but not on the exploitation of entrepreneurial opportunities. We interpret this result as meaning that although scientific research excellence may be an important factor (or starting point) for the capacity to contribute to technological advances through research and to the exploration of entrepreneurial opportunities, there are counter-factors such as the rights to publish (and exploit) research outcomes (e.g. Blumenthal et al., 1997), and the uncertainty regarding the immediacy of the research for development into a commercial application (e.g. Gulbrandsen and Smeby, 2005). These factors may reduce the likelihood of the academic exploiting these opportunities. In other words, while scientific excellence is relevant for opportunity discovery and the exploration of entrepreneurial opportunities, something more than excellent science is needed for opportunity exploitation. 


\section{b) Combining multiple bodies of knowledge}

Our results indicate that individuals able to combine multiple fields of research will be more likely to complement their specialist scientific knowledge to exploit their technology inventions and produce saleable goods and services. In other words, academics whose research activities draw on multiple bodies of knowledge and who are able to establish associations between their research expertise and business related activities, will be better equipped to exploit the commercial opportunities resulting from their research, for example, by creating spin-offs, than more narrowly specialized researchers.

\section{c) Prior invention experience}

Our results strongly support the view that prior experience in invention-related activities matters for future academic entrepreneurship. There is a clear reinforcing effect on those academics who have been involved in invention, which makes them more likely to contribute to the pool of technological opportunities and explore potential entrepreneurial opportunities in their research results, and more able to engage with the intricacies of exploitation of these opportunities. To what extent repeat entrepreneurs exhibit unique features compared to sporadic entrepreneurs and non-entrepreneurial academics or what are the factors that favour recurrent academic entrepreneurship are both questions for future research.

d) Collaboration with users and networking

While collaboration and networking are important factors in academic entrepreneurship (Shane, 2000; Nicolau and Birley, 2003; Bercovitz and Feldman, 
2008), the types of networks matter. Our results indicate that it is important to establish collaborations with potential users (especially businesses) in order to develop the skills required for entrepreneurship, while research collaboration networks seem to have a minor impact on the development of these skills. Our results show that prior experience of collaboration with users has a much stronger impact on the exploitation of entrepreneurial opportunities (as opposed to the discovery of technological opportunities). This indicates that this type of collaboration equips academic researchers with the sets of complementary skills necessary to engage in highly complex and risky entrepreneurial activities, such as developing marketable products/services and establishing viable business strategies.

Overall, our results confirm our initial proposition that discovery of technological opportunities and exploitation of entrepreneurial opportunities are shaped by different factors associated with the scientists' skills and idiosyncratic experience. We believe these results are important for a better understanding of the phenomenon of academic entrepreneurship, and should contribute to the design of policies aimed at building a favourable climate for knowledge exchange and university-business interactions.

This article has a number of limitations which open the way for future research. First, although the study finds strong evidence for scientific breadth promoting entrepreneurship, it does not rule out alternative explanations. An extension of this work could disentangle whether unobserved heterogeneity is driving the relationships found in this study (e.g. psychological individual attributes such as tolerance of risk and ambiguity). Second, our result that the academic research network of the scientist does not influence the probability of opportunity exploitation may depend on the way 
in which the network is defined. We considered the network of the scientist proxied by the co-publication activity of researchers, but this measure may be biased in favour of academic organizations - although it does not rule out the possibility of collaboration with non-academic institutions. We acknowledge that our measure is a rough proxy for the academic researcher's wider social network. It also explains why our results contrast with those in Nicolaou and Birley (2003), which takes account of both endoinstitutional and exoinstitutional ties and shows that the exoinstitutional ties are important in influencing the type of spinout initiated. Our measure is likely to be biased toward endoinstitutional ties and, for this reason, does not capture the effect of the academic research network on the exploitation of entrepreneurial opportunities. Finally, our study only indirectly explores whether the incentive structures under which academics operate moderate their willingness or capacity to engage in entrepreneurship. This should be considered explicitly in further research. 


\section{ACKNOWLEDGEMENT}

We gratefully acknowledge financial support from the Innovation \& Productivity Grand Challenge (IPGC) project under the Advance Institute of Management (AIM) UK, ESRC UK and EPSRC UK. 


\section{REFERENCES}

Abreu, M., Grinevich, V., Hughes, A. and Kitson, M. 2009, Knowledge Exchange between Academics and the Business, Public and Third Sectors, Centre for Business Research, University of Cambridge, Cambridge.

Aldrich, H.E., Rosen B., Woodward W. 1987. The impact of social networks on business founding and profit. Frontiers of Entrepreneurship Research. Babson College, Wellesley, MA.

Bammer, G. 2008. Enhancing research collaborations: three key management challenges. Research Policy 37 (5), 875-887.

Barker, K. 2007. The UK Research Assessment Exercise: the evolution of a national research evaluation system. Research Evaluation 16 (1), 3-12.

Bercovitz, J., Feldman, M. 2008. Academic entrepreneurs: organizational change at the individual level. Organization Science 19 (1), 69-89

Bierly, P., Damanpour, F. and Santoro, M. 2009. The application of external knowledge: organizational conditions for exploration and exploitation. Journal of Management Studies 46:(3), 481-509.

Blumenthal, D., Campbell, E.G., Anderson, M.S., Causino, N., Louis, K.S. 1997.

Withholding research results in academic life science - evidence from a national survey. The Journal of the American Medical Association 277 (15), $1224-1228$.

Chrisman, J.J., Hynes, T., Fraser, S. 1995. Faculty entrepreneurship and economic development: the case of the university of Calgary. Journal of Business Venturing 10 (4), 267-281. 
Colyvas, J., Crow, M., Gelijns, A., Mazzoleni, R., Nelson, R.R., Rosenberg, N., Sampat, B.N. 2002. How do university inventions get into practice? Management Science 48 (1), 61-72.

Crespi, G., D’Este, P., Fontana, R., Geuna, A. 2011. The impact of academic patenting on university research and its transfer. Research Policy 40 (1), 5568.

Deeds, D.L., Decarolis, D., Coombs, J.E. 1997. The impact of firm specific capabilities on the amount of capital raised in an initial public offering : evidence from the biotechnology industry. Journal of Business Venturing 12 (1), 31-46.

Di Gregorio, D., Shane, S. 2003. Why do some universities generate more start-ups than others? Research Policy 32 (2), 209-227.

Eckhardt, J. \& Shane, S. 2003. Opportunities and entrepreneurship, Journal of Management 29(3), 333-349.

Etzkowitz, H. 1989. Entrepreneurial science in the academy - a case of the transformation of norms. Social Problems 36 (1), 14-29.

Feldman, M., Desrochers, P. 2004. Truth for its own sake: academic culture and technology transfer at Johns Hopkins University. Minerva 42, 105-126.

Fini, R.; Lacetera, N. \& Shane, S. 2010. Inside or outside the IP system? Business creation in academia. Research Policy 39 (8), 1060-1069.

Franzoni, C., and Lissoni, F. 2007. Academic entrepreneurship, patents, and spin-offs: critical issues and lessons for Europe, in Varga A. (Ed.), Universities and regional economic development, Cheltenham: Edward Elgar. 
Grandi, A., Grimaldi, R. 2005. Academics' organizational characteristics and the generation of successful business ideas. Journal of Business Venturing 20, $821-845$.

Griliches, Z. 1990. Patent Statistics as Economic Indicators: a Survey. Journal of Economic Literature 28 (4), 1661-1707.

Gulbrandsen, M., Smeby, J.C. 2005. Industry funding and university professors' research performance. Research Policy 34 (6), 932-950.

Hills, G.E., Lumpkin, G.T., Singh, R.P. 1997. Opportunity recognition: perceptions and behaviours of entrepreneurs. Frontiers of Entrepreneurship Research. Babson College, Wellesley, MA.

Hoye, K., Pries, F. 2009. 'Repeat commercializers', the 'habitual entrepreneurs' of university-industry technology transfer. Technovation 29, 682-689.

Jensen, R., Thursby, M. 2001. Proofs and prototypes for sale: the licensing of university inventions. American Economic Review 91, 240-259.

Jensen, R.A., Thursby, J.G., Thursby, M.C. 2003. Disclosure and licensing of University inventions: 'The best we can do with the $\mathrm{s}^{* *} \mathrm{t}$ we get to work with'. International Journal of Industrial Organization 21, 1271-1300.

Jong, S. 2006. How organizational structures in science shape spin-off firms: the biochemistry departments of Berkeley, Stanford, and UCSF and the birth of the biotech industry. Industrial and Corporate Change 115 (2), 251-283.

Klevorick, A.; Levin, R.; Nelson, R. \& Winter, S. 1995. On the sources and significance of inter-industry differences in technological opportunities. Research policy 24 (2), 185-205. 
Landry, R., Amara, N., Ouimet, M. 2007. Determinants of knowledge transfer: evidence from the Canadian university researchers in natural sciences and engineering. Journal of Technology Transfer 32, 561-592.

Landry, R., Saihi, M., Amara, N. and Ouimet, M. 2010. Evidence On How Academics Manage Their Portfolio Of Knowledge Transfer Activities, Research Policy 39 (10), 1387-1403

Lockett A and Wright M. 2005. Resources, capabilities risk capital and the creation of university spinout companies. Research Policy 34, 1043-1057.

Louis, K.S., Blumenthal, D., Gluck, M.E., Stoto, M.A. 1989. Entrepreneurs in academe: an exploration of behaviours among Life scientists. Administrative Science Quarterly 34 (1), 110-131.

Lowe, R. \& Ziedonis, A. 2006. Overoptimism and the performance of entrepreneurial firms. Management Science 52 (2), 173-186.

Lubango, L.M., Pouris, A. 2007. Industry work experience and inventive capacity of South African academic researchers. Technovation 27, 788-796.

Mahdi, S., D’Este, P., Neely, A. 2008. Citation Counts: Are They Good Predictors of RAE Scores? A bibliometric analysis of RAE 2001, London: AIM Report.

Mansfield, E. 1995. Academic Research Underlying Industrial Innovations: Sources, Characteristics, and Financing. Review of Economics and Statistics 77 (1), 5565.

Meyer, M. 2006. Are patenting scientists the better scholars? An exploratory comparison of inventor-authors with their non-inventing peers in nano-science and technology. Research Policy 35 (10), 1646-1662. 
Mowery, D.C., Sampat, B.V. 2005. The Bayh-Dole Act of 1980 and universityindustry technology transfer: a model for other OECD Governments? Journal of Technology Transfer 30 (1/2), 115-127.

Murray, F. \& Stern, S. 2007. Do formal intellectual property rights hinder the free flow of scientific knowledge?: An empirical test of the anti-commons hypothesis. Journal of Economic Behavior \& Organization 63 (4), 648-687.

Mustar, P. 1997. How French academics create hi-tech companies: the conditions for success and failure. Science and Public Policy 24 (1), 37-43.

Nicolau, N., Birley, S. 2003. Academic networks in a trichotomous categorisation of university spinouts. Journal of Business Venturing 18 (3), 333-359.

OECD. 2003. Turning science into business, patenting and licensing at public research organisations. OECD: Paris.

Park, J.S. 2005. Opportunity recognition and product innovation in entrepreneurial hitech start-ups: a new perspective and supporting case study. Technovation 25 , $739-752$.

Powers, J.B., McDougall, P.P. 2005. University start-up formation and technology licensing with firms that go public: a resource-based view of academic entrepreneurship. Journal of Business Venturing 20 (3), 291-311.

Prodan, I. \& Drnovsek, M. 2010. Conceptualizing academic-entrepreneurial intentions: An empirical test. Technovation 30 (5-6), 332-347.

Rafols, I. 2008. Strategies for knowledge acquisition in bionanotechnology. Why are interdisciplinary practices less widespread than expected? Innovation 20 (4), $395-412$.

Rothaermel, F.T., Agung, S.D., Jiang, L. 2007. University entrepreneurship: a taxonomy of the literature. Industrial and Corporate Change 16 (4), 691-791. 
Shane, S. 2000. Prior knowledge and the discovery of entrepreneurial opportunities. Organization Science 11 (4), 448-469.

Shane, S. 2001a. Technology regimes and new firm formation. Management Science 47 (9), 1173-1190.

Shane, S. 2001b. Technological Opportunities and New Firm Creation. Management Science 47 (2), 205-229.

Shane, S. 2002. Selling university technology: patterns from MIT. Management Science 48 (1), 122-137.

Shane, S., Venkataraman, S. 2000. The promise of entrepreneurship as a field of research. Academy of Management Review 25 (1), 217-226.

Siegel, D.S. 2006. Technology entrepreneurship: institutions and agents involved in university technology transfer. Vol 1. Edward Elgar: London.

Siegel, D.S., Waldman, D., Link, A. 2003. Assessing the impact of organizational practices on the productivity of university technology transfer offices: an exploratory study. Research Policy 32 (1), 27-48.

Stuart, T.E., Ding, W.W. 2006. When do scientists become entrepreneurs ? The social structural antecedents of commercial activity in the academic life sciences. American Journal of Sociology 112 (1), 97-144.

Tijssen, R.J.W. 2006. Universities and industrially relevant science: toward measurement models and indicators of entrepreneurial orientation. Research Policy 35 (10), 1569-1585.

Tornquist, K.M., Kallsen, L.A. 1994. Out of the ivory tower: characteristics of institutions meeting the research needs of industry. Journal of Higher Education 65 (5), 523-539. 
Uzzi, B. 1997. Social structure and competition in interfirm networks: the paradox of embededness. Administrative Science Quarterly 42, 33-67.

Venkataraman, S. 1997. The distinctive domain of entrepreneurship research: an editor's perspective. In Katz J and Brockhaus R. (eds.) Advances in entrepreneurship, firm emergence and growth. Vol.3: 119-138. Greenwhich, CT: JAI Press.

Whitley, R. 2007. The changing governance of the public sciences: the consequences of research evaluation systems. In Whitley R., Glaser J. and Barker K. (eds.) The changing governance of the sciences: the advent of research evaluation systems. Springer; 2007.

Wright, M., Birley, S., Mosey, S. 2004. Entrepreneurship and university technology transfer. Journal of Technology Transfer 29, 235-246.

Wright, M., Clarysse, B., Mustar, P., Lockett, A. 2007. Academic entrepreneurship in Europe. Edward Elgar: Cheltenham, UK.

Wu, J. and Shanley, M. T. 2009. Knowledge stock, exploration, and innovation: Research on the United States electromedical device industry, Journal of Business Research 62 (4), 474-483.

Zucker, L.G., Darby, M.R., Brewer, M.B. 1998. Intellectual human capital and the birth of US Biotechnology enterprises. The American Economic Review 88 (1), 290-306.

Zucker, L.; Darby, M. \& Armstrong, J. 2002. Commercializing Knowledge: University Science, Knowledge Capture, and Firm Performance in Biotechnology. Management Science 48 (1), 138-153. 
Table 1. Proportion of our 'final sample' relative to the population surveyed

\begin{tabular}{|c|c|c|c|c|c|}
\hline Disciplines & $\begin{array}{c}\text { Population } \\
\text { surveyed } \\
\text { (A) }\end{array}$ & $\begin{array}{c}\text { Survey } \\
\text { respondents } \\
\text { (B) }\end{array}$ & $\begin{array}{c}\text { Response } \\
\text { rate }(\%) \\
(\mathrm{A} / \mathrm{B}) \\
\end{array}$ & $\begin{array}{c}\text { Survey-WoS } \\
\text { Matched Sample } \\
\text { (C) }\end{array}$ & $\begin{array}{c}\% \text { Population } \\
\text { Surveyed } \\
(\mathrm{C} / \mathrm{A})\end{array}$ \\
\hline Chemical Engineering & 174 & 62 & 35.6 & 39 & 22.4 \\
\hline Chemistry & 754 & 271 & 35.9 & 205 & $27.2 *$ \\
\hline Civil Engineering & 242 & 86 & 35.5 & 42 & 17.4 \\
\hline Computer Science & 536 & 162 & 30.2 & 39 & $7.3 *$ \\
\hline Electrical \& Electronic Eng. & 496 & 172 & 34.7 & 98 & 19.8 \\
\hline General Engineering & 292 & 116 & 39.7 & 70 & 23.9 \\
\hline Mathematics & 563 & 216 & 38.4 & 129 & 22.9 \\
\hline Mechanical, Aero \& Manuf. Eng. & 484 & 179 & 37.0 & 109 & 22.5 \\
\hline Metallurgy \& Materials & 201 & 69 & 34.3 & 53 & 26.4 \\
\hline Physics & 595 & 195 & 32.8 & 132 & 22.2 \\
\hline Total & 4,337 & 1,528 & 35.2 & 916 & 21.1 \\
\hline
\end{tabular}

Note: $*$ indicates that the proportion of cases in a particular discipline that appears in our final matched-sample, is significantly higher/lower than the proportion of cases (that appears in the final matched-sample) for all other disciplines combined (using Chi-square tests at the 5\% level of significance).

Table 2. Percentage of university researchers involved in opportunity exploration and opportunity exploitation, by scientific discipline

\begin{tabular}{|c|c|c|c|}
\hline Disciplines & $\begin{array}{c}\text { Opportunity } \\
\text { Discovery } \\
\text { (Inventions) }(\%) \\
\end{array}$ & $\begin{array}{c}\text { Opportunity } \\
\text { Exploitation } \\
\text { (Spin-offs) }(\%)\end{array}$ & $\begin{array}{c}\text { Number of } \\
\text { university } \\
\text { researchers } \\
\end{array}$ \\
\hline Chemical Engineering & 33.3 & 15.4 & 39 \\
\hline Chemistry & 35.6 & 9.8 & 205 \\
\hline Civil Engineering & 16.7 & 16.7 & 42 \\
\hline Computer Science & 12.8 & 15.4 & 39 \\
\hline Electrical \& Electronic Eng. & 48.0 & 23.5 & 98 \\
\hline General Engineering & 35.7 & 24.3 & 70 \\
\hline Mathematics & 3.9 & 1.6 & 129 \\
\hline Mechanical, Aero \& Manufact. Eng. & 30.3 & 22.0 & 109 \\
\hline Metallurgy \& Materials & 37.7 & 15.1 & 53 \\
\hline Physics & 29.5 & 8.3 & 132 \\
\hline Total & $29.1 \%$ & $13.5 \%$ & 916 \\
\hline
\end{tabular}


Table 3. Descriptive statistics and correlations ${ }^{*}$

\begin{tabular}{|c|c|c|c|c|c|c|c|c|c|c|c|c|c|c|c|c|c|c|c|}
\hline Variable & Mean & S. Dev. & Median & Min. & Max. & 1 & 2 & 3 & 4 & 5 & 6 & 7 & 8 & 9 & 10 & 11 & 12 & 13 & 14 \\
\hline 1. Opportunity Discovery & 0.29 & 0.45 & 0 & 0 & 1 & & & & & & & & & & & & & & \\
\hline 2. Opportunity Exploitation & 0.14 & 0.34 & 0 & 0 & 1 & 0.364 & & & & & & & & & & & & & \\
\hline 3. Collaboration with industry & 1.06 & 1.49 & 1 & 0 & 13 & 0.186 & 0.199 & & & & & & & & & & & & \\
\hline 4. Invention Experience & 0.24 & 0.95 & 0 & 0 & 12 & 0.304 & 0.216 & 0.303 & & & & & & & & & & & \\
\hline 5. Scientific breadth & 0.87 & 0.42 & 0.75 & 0.25 & 2.67 & 0.016 & 0.137 & 0.095 & 0.016 & & & & & & & & & & \\
\hline 6. Scientific Excellence & 12.27 & 16.32 & 7 & 0 & 209.75 & 0.082 & -0.024 & -0.043 & 0.041 & -0.149 & & & & & & & & & \\
\hline 7. Research Network (Ln) & 0.7 & 0.53 & 0.5 & 0 & 7.5 & -0.083 & -0.037 & -0.055 & -0.024 & -0.067 & 0.188 & & & & & & & & \\
\hline 8. Behavioural Motivations & 3.69 & 0.88 & 3.83 & 1 & 5 & 0.236 & 0.165 & 0.282 & 0.167 & 0.092 & 0.027 & -0.136 & & & & & & & \\
\hline 9. Age & 46.54 & 9.85 & 45 & 24 & 75 & 0.043 & 0.049 & 0.206 & 0.082 & 0.085 & -0.058 & -0.044 & 0.147 & & & & & & \\
\hline 10. Department Size (Ln) & 3.47 & 0.69 & 3.43 & 1.1 & 5.12 & 0.107 & 0.039 & 0.069 & 0.045 & -0.006 & 0.187 & -0.022 & 0.127 & -0.012 & & & & & \\
\hline 11. Industry fund. P.c. (Ln) & 3.24 & 1.35 & 3.65 & 0 & 5.39 & 0.232 & 0.170 & 0.294 & 0.138 & 0.182 & -0.050 & -0.148 & 0.355 & 0.024 & 0.278 & & & & \\
\hline 12. Top rank department & 0.29 & 0.46 & 0 & 0 & 1 & 0.035 & 0.046 & 0.074 & 0.009 & 0.019 & 0.091 & -0.072 & 0.136 & 0.052 & 0.440 & 0.118 & & & \\
\hline 13. Low rank department & 0.28 & 0.45 & 0 & 0 & 1 & 0.009 & -0.004 & -0.002 & -0.018 & 0.102 & -0.081 & 0.001 & -0.014 & -0.013 & -0.342 & 0.041 & -0.401 & & \\
\hline 14. Russell Group & 0.54 & 0.5 & 1 & 0 & 1 & 0.004 & -0.035 & 0.039 & 0.031 & -0.096 & 0.077 & 0.027 & -0.002 & -0.030 & 0.299 & 0.011 & 0.340 & -0.419 & \\
\hline 15. Spin-off Mechanisms & 5.83 & 1.35 & 6 & 0 & 7 & 0.001 & 0.004 & 0.045 & 0.014 & 0.023 & -0.030 & -0.039 & 0.054 & 0.034 & 0.114 & 0.092 & 0.006 & 0.054 & -0.063 \\
\hline
\end{tabular}

* Number of observations equals 916. 
Table 4. Results of Probit Regression Analyses: factors influencing discovery of technological opportunities and exploitation of entrepreneurial opportunities

\begin{tabular}{|c|c|c|}
\hline & $\begin{array}{c}\text { Opportunity } \\
\text { Discovery }\end{array}$ & $\begin{array}{l}\text { Opportunity } \\
\text { Exploitation }\end{array}$ \\
\hline Scientific Excellence & $\begin{array}{l}0.007 * * \\
(0.003)\end{array}$ & $\begin{array}{c}0.003 \\
(0.004)\end{array}$ \\
\hline Scientific breadth & $\begin{array}{c}0.088 \\
(0.130)\end{array}$ & $\begin{array}{c}0.414 * * * \\
(0.138)\end{array}$ \\
\hline Prior Invention Experience & $\begin{array}{c}0.631 * * * \\
(0.132)\end{array}$ & $\begin{array}{c}0.202 * * * \\
(0.056)\end{array}$ \\
\hline Past Collaboration with industry & $\begin{array}{c}0.033 \\
(0.038)\end{array}$ & $\begin{array}{l}0.084^{* * *} \\
(0.039)\end{array}$ \\
\hline Research Network & $\begin{array}{l}-0.053 \\
(0.042)\end{array}$ & $\begin{array}{c}0.020 \\
(0.058)\end{array}$ \\
\hline Behavioural Motivation & $\begin{array}{c}0.215 * * * \\
(0.065)\end{array}$ & $\begin{array}{c}0.183^{* * *} \\
(0.078)\end{array}$ \\
\hline Age & $\begin{array}{l}-0.000 \\
(0.005)\end{array}$ & $\begin{array}{c}0.000 \\
(0.006)\end{array}$ \\
\hline Size Department & $\begin{array}{c}0.045 \\
(0.110)\end{array}$ & $\begin{array}{l}-0.046 \\
(0.124)\end{array}$ \\
\hline Industry Funding p.c. & $\begin{array}{c}0.177^{* *} \\
(0.074)\end{array}$ & $\begin{array}{c}0.057 \\
(0.096)\end{array}$ \\
\hline Top Ranked Department & $\begin{array}{c}0.029 \\
(0.143)\end{array}$ & $\begin{array}{c}0.154 \\
(0.163)\end{array}$ \\
\hline Low Ranked Department & $\begin{array}{c}0.079 \\
(0.143)\end{array}$ & $\begin{array}{l}-0.012 \\
(0.163)\end{array}$ \\
\hline Russell Group Univ. & $\begin{array}{l}-0.045 \\
(0.121)\end{array}$ & $\begin{array}{l}-0.101 \\
(0.141)\end{array}$ \\
\hline Spin-off Mechanisms & $\begin{array}{l}-0.043 \\
(0.076)\end{array}$ & $\begin{array}{l}-0.087 \\
(0.089)\end{array}$ \\
\hline Discipline dummies & Included & Included \\
\hline Regional dummies & Included & Included \\
\hline Constant & $\begin{array}{c}-2.308 * * * \\
(0.780)\end{array}$ & $\begin{array}{c}-2.147 * * \\
(0.935)\end{array}$ \\
\hline $\begin{array}{l}\text { Log-likelihood } \\
\text { Chi }^{2} \\
\text { Mc Fadden's } R^{2} \\
\text { Observations }\end{array}$ & $\begin{array}{c}-434.316 \\
127.008 \\
0.193 \\
886 \\
\end{array}$ & $\begin{array}{c}-297.299 \\
113.373 \\
0.163 \\
886 \\
\end{array}$ \\
\hline
\end{tabular}

Note: Unstandardised coefficients are reported, with robust standard errors in parentheses. $* p<0.1,{ }^{* *} p<0.05,{ }^{* * *} p<0.01$. 
Appendix.

Table A1. Results of bivariate probit analysis.

\begin{tabular}{|c|c|c|}
\hline & $\begin{array}{c}\text { Opportunity } \\
\text { Discovery }\end{array}$ & $\begin{array}{l}\text { Opportunity } \\
\text { Exploitation }\end{array}$ \\
\hline Scientific Excellence & $\begin{array}{l}0.007 * * \\
(0.003)\end{array}$ & $\begin{array}{c}0.002 \\
(0.004)\end{array}$ \\
\hline Scientific breadth & $\begin{array}{c}0.096 \\
(0.126)\end{array}$ & $\begin{array}{c}0.419 * * * \\
(0.145)\end{array}$ \\
\hline Prior Invention Experience & $\begin{array}{c}0.624 * * * \\
(0.106)\end{array}$ & $\begin{array}{c}0.192 * * * \\
(0.057)\end{array}$ \\
\hline Past Collaboration with industry & $\begin{array}{c}0.028 \\
(0.037)\end{array}$ & $\begin{array}{c}0.089 * * \\
(0.039)\end{array}$ \\
\hline Research Network & $\begin{array}{l}-0.050 \\
(0.043)\end{array}$ & $\begin{array}{c}0.023 \\
(0.052)\end{array}$ \\
\hline Behavioural Motivation & $\begin{array}{c}0.214 * * * \\
(0.064)\end{array}$ & $\begin{array}{c}0.216 * * * \\
(0.079)\end{array}$ \\
\hline Age & $\begin{array}{l}-0.000 \\
(0.005)\end{array}$ & $\begin{array}{l}-0.003 \\
(0.006)\end{array}$ \\
\hline Size Department & $\begin{array}{c}0.036 \\
(0.114)\end{array}$ & $\begin{array}{l}-0.041 \\
(0.131)\end{array}$ \\
\hline Industry Funding p.c. & $\begin{array}{c}0.169 * * \\
(0.074)\end{array}$ & $\begin{array}{c}0.043 \\
(0.085)\end{array}$ \\
\hline Top Ranked Department & $\begin{array}{c}0.039 \\
(0.145)\end{array}$ & $\begin{array}{c}0.187 \\
(0.167)\end{array}$ \\
\hline Low Ranked Department & $\begin{array}{c}0.082 \\
(0.142)\end{array}$ & $\begin{array}{c}0.012 \\
(0.169)\end{array}$ \\
\hline Russell Group Univ. & $\begin{array}{l}-0.037 \\
(0.127)\end{array}$ & $\begin{array}{l}-0.090 \\
(0.146)\end{array}$ \\
\hline Spin-off Mechanisms & $\begin{array}{l}-0.040 \\
(0.075)\end{array}$ & $\begin{array}{l}-0.082 \\
(0.087)\end{array}$ \\
\hline Discipline dummies & Included & Included \\
\hline Regional dummies & Included & Included \\
\hline Constant & $\begin{array}{c}-2.281 * * * \\
(0.773)\end{array}$ & $\begin{array}{c}-2.185^{* *} \\
(0.898) \\
\end{array}$ \\
\hline $\begin{array}{l}\text { Log-likelihood } \\
\text { Chi }^{2} \\
\text { Observations }_{\text {Log-likelihood }} \\
\text { Rho }\end{array}$ & & \\
\hline
\end{tabular}

Note: Two tailed t-test: ${ }^{*} \mathrm{p}<0.10 ;{ }^{* *} \mathrm{p}<0.05 ;{ }^{* * *} \mathrm{p}<0.01$. Standard errors between brackets. 